\title{
Extensive intraspecific polymorphism detected by SSCP at the nuclear C-mos gene in the endemic Iberian lizard Lacerta schreiberi
}

\author{
RAQUEL GODINHO,$*$ VERA DOMINGUES, ${ }^{*}$ EDUARDO G. CRESPO† and NUNO FERRAND*§ \\ *CIBIO - Centro de Investigação em Biodiversidade e Recursos Genéticos, Campus Agrário de Vairão, 4485-661 Vairão, Portugal, \\ +Centro de Biologia Ambiental e Departamento de Biologia Animal, Faculdade de Ciências da Universidade de Lisboa. Campo \\ Grande, 1749-016 Lisboa, Portugal, łUnidade de Investigacão em Eco-etologia. I.S.P.A., R. Jardim do Tabaco 34, 1149-041 Lisboa, \\ Portugal, §Departamento de Zoologia e Antropologia, Faculdade de Ciências, Universidade do Porto, Praça Gomes Teixeira. \\ 4099-002 Porto, Portugal
}

\begin{abstract}
C-mos is a highly conserved intronless gene that has proved useful in the analysis of ancient phylogenetic relationships within vertebrates. We selected the Iberian endemic Schreiber's green lizard (Lacerta schreiberi) that persisted in allopatric refugia since the late Pliocene to investigate the utility of the C-mos nuclear gene for intraspecific phylogeographic studies. Our combination of DNA sequencing with the high resolving power of single-strand conformational polymorphism (SSCP) effectively discriminated four common alleles showing strong population structuring $\left(F_{\mathrm{ST}}=0.46\right)$. In addition, reconstruction of allele phylogenetic relationships further improved our understanding of C-mos spatial patterns of variation and allowed a comparison with previously described mitochondrial DNA data. Finally, limited sequencing of an extended C-mos fragment in six additional Lacerta species showed extensive polymorphism, to our knowledge representing a rare example of variation in a highly conserved nuclear gene.
\end{abstract}

Keywords: intraspecific polymorphism, Lacerta schreiberi, nuclear gene, C-mos, SSCP

Received 24 August 2005; revision accepted 20 October 2005

\section{Introduction}

Reconstructing patterns of genetic differentiation and past colonization routes of organisms has been simplified in the last years with the progressive improvement of molecular techniques (Avise 2000). Currently, phylogeographic studies are generalized and most of them involve analyses of animal mitochondrial DNA (mtDNA). The peculiarities of mtDNA inheritance mode (maternal and nonrecombinant) and the rapid evolution of its sequences are at the origin of this success since they often provide multiple haplotypes that can be ordered phylogenetically within a species (Avise 2000). Nevertheless, the matrilineal phylogeny registered by this molecule represents only a very small fraction of the total historical record within a sexual organismal pedigree (Avise 1998; Zhang \& Hewitt 2003), as well as a sex-biased look at this record-dispersal and gene flow are

Correspondence: Raquel Godinho, Fax: +351 252 661780; E-mail: rgodinho@mail.icav.up.pt highly asymmetric by gender in many species, with females commonly philopatric to natal sites. While the use of autosomal loci for phylogeographic purposes is still dominated by relevant challenges that include (i) the identification of genomic regions with suitable rapid evolution, (ii) the possibility of intragenic recombination, and (iii) the technical problems of isolating haplotypes one at a time from diploid DNA (Zhang \& Hewitt 2003), the important limitations of mtDNA-based phylogeography have emphasized the need of acquiring information from multiple nuclear loci before drawing firm phylogeographic conclusions for any species.

Mos (E.C. 2.7.1.-) is a serine/threonine kinase with a mass of approximately $39 \mathrm{kDa}$ that result from the expression of the nuclear C-mos proto-oncogene. This kinase is known to be a key regulator of the meiotic process of vertebrate oocytes (Sagata et al. 1988; Gebauer \& Richter 1997). Therefore, the C-mos gene is expressed at high levels in germ cells and at very low levels, if any, in somatic cells. When expressed in somatic cells, however, the protein 
product can readily induce oncogenic transformation of the cells (see review by Sagata 1997). In the genomes of species ranging from amphibians to humans, C-mos is present as a single coding exon of approximately $2 \mathrm{~kb}$ (Yew et al. 1993), making it an attractive tool in phylogenetic studies. To date, C-mos has been almost exclusively used as a molecular marker in deep phylogenetic studies relating orders (Cooper \& Penny 1997; Hedges \& Poling 1999; García-Moreno et al. 2003) or families (Saint et al. 1998; Harris et al. 1999; Hughes \& Baker 1999; Barker et al. 2001). More recently, however, the general belief that C-mos is a slow-evolving gene, coherent with its pivotal role in cell cycle, was re-evaluated when substantial progress in resolving relationships of passerine genera was provided (Lovette \& Bermingham 2000).

It is well known that certain regions of the Iberian Peninsula were Pleistocene refugia for many plants and animals, even during the most extreme glacial periods. For species that were originally from Iberia, the glacial times, together with the geographical and topographical heterogeneity of the peninsula, favoured repeated fragmentation of initial distribution areas over time, thus providing opportunities for differentiation (Blondel \& Aronson 1999). This fact promoted regional differentiation at various levels of organization, ranging from the more simple genetic structuring of populations to the more complex processes of subspeciation, or even speciation. Examples of this have been described for a variety of organisms that include the Mediterranean ragwort, Senecio gallicus (Comes \& Abbott 1998), the European rabbit, Oryctolagus cuniculus (Branco et al. 2000, 2002), the golden-striped salamander, Chioglossa lusitanica (Alexandrino et al. 2000, 2002), and the Schreiber's green lizard, Lacerta schreiberi (Godinho et al. 2001; Paulo et al. 2001, 2002). This last species is endemic to Iberia with a distribution restricted to the northwestern part of this peninsula and with several isolated populations in southern mountains where is generally found near water courses in Atlantic forest areas with high precipitation and mild winters. Preliminary work with L. schreiberi using mtDNA cytochrome $b$ revealed high levels of phylogeographic structuring with two very different allopatric lineages exhibiting sequence divergence ranging from $4.1 \%$ to 7.2\% (Paulo et al. 2001). This deep mtDNA phylogenetic disjunction distinguishes Portuguese and northern Spain populations from those in the Spanish central system and probably correspond to a long isolation period that started in the late Pliocene (Paulo et al. 2001). Despite relevant differences in their effective population size and the stochastic variance associated to any sampling of independent gene trees (Hudson \& Turelli 2003), it is thus to be expected that to this depth of $\mathrm{mtDNA}$ divergence could correspond a genetic imprint in the nuclear genome of this species, including those genes that were described as very conservative.

In this study, we describe the utility of the C-mos gene for a phylogeographic study using L. schreiberi as a model. We document the spatial distribution of C-mos variability in 19 populations sampled throughout the entire species' range using single-strand conformational polymorphism (SSCP) and compare the phylogeographic pattern generated with these data with that from both mtDNA and protein polymorphisms. Additionally, we sequenced some individuals of other Lacerta species (two to three per species from different localities) to better evaluate the relevance of our findings and to reconstruct a phylogeny of the alleles found for L. schreiberi.

\section{Materials and methods}

\section{Sampling and DNA extraction}

Lacerta schreiberi samples were collected in 19 localities across the species' distribution area (Fig. 1), representing a total of 414 samples. Animals were released at the capture site. DNA extraction was performed following the Sambrook et al. (1989) protocol.

\section{$P C R$ amplification of $C$-mos and sequencing}

Polymerase chain reaction (PCR) primers were designed by eye using sequences from three reptile families (Scincidae, Iguanidae and Agamidae) and the chicken, all available in GenBank. The gene regions for the primer design were selected for their conserved amino acid sequences and relatively low required degeneracy. Primer lengths were optimized to achieve approximately equal

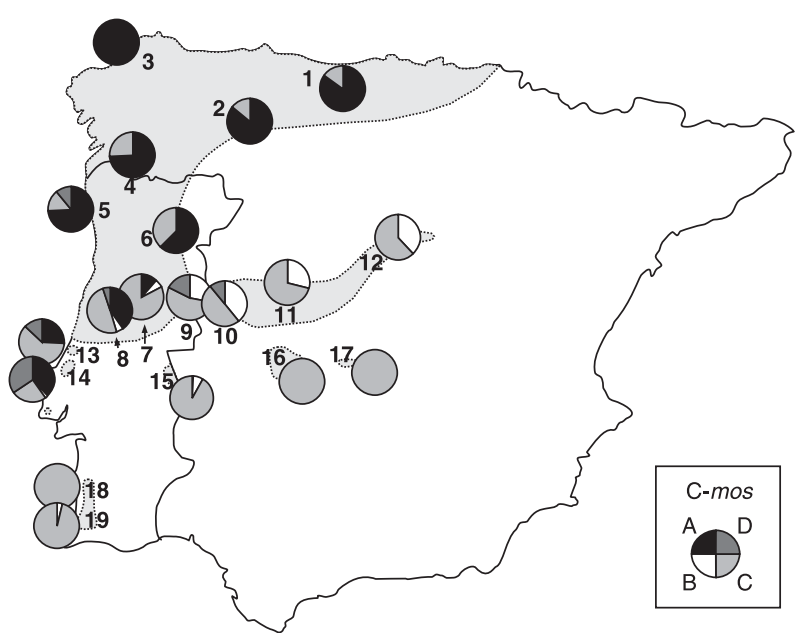

Fig. 1 Sampling locations of Lacerta schreiberi in the Iberian Peninsula. 1, Astúrias; 2, Ancares; 3, El Ferrol; 4, Gerês; 5, Gião; 6, Montemuro; 7, Estrela; 8, Lousã; 9, Malcata; 10, Gata; 11, Béjar; 12, Guadarrama; 13, C. Rainha; 14, Montejunto; 15, S. Mamede; 16, Guadalupe; 17, Toledo; 18, Cercal; 19, Monchique. The shaded area of the map represents the current distribution of the species. Pie charts represent the approximate frequencies of C-mos alleles. 
estimates for annealing temperature. The forward primer, Mos-F, was a 29-mer with sequence 5'-CTCTGGKGGCTTTGGKKCTGTSTACAAGG-3' [443], and the reverse primer, Mos-R, was a 27-mer with sequence $5^{\prime}$-GGTGATGGCAAANGAGTAGATGTCTGC-3' [1044]. Numbers in brackets after the primer refer to the $5^{\prime}$ position of the primer, as localized on the nucleotide sequence of the human C-mos gene (J00119). PCR conditions were optimized using a Robocycler Gradient 96 (Stratagene) and the thermal profile was defined as $3 \mathrm{~min}$ at $95^{\circ} \mathrm{C}$ followed by 30 cycles at $95^{\circ} \mathrm{C}$ for $1 \mathrm{~min}, 60^{\circ} \mathrm{C}$ for $1 \mathrm{~min}$, and $72{ }^{\circ} \mathrm{C}$ for $1 \mathrm{~min}$. A 5-min extension at $72{ }^{\circ} \mathrm{C}$ was added on the end of the reaction. PCR amplifications were performed in $25-\mu \mathrm{L}$ total volume, with $0.08 \mathrm{U}$ of Taq polymerase (Promega), 12 pmol of each primer, $3 \mathrm{~mm} \mathrm{MgCl}_{2}$ and $0.2 \mathrm{~mm}$ of each dNTP. The resulting single PCR bands of $578 \mathrm{bp}$ were sequenced for both strands with the PCR primers on an ABI PRISM 310 Genetic Analyser (PE Applied Biosystems) following the ABI PRISM BigDye Terminator Cycle sequencing protocols. Centrisep spin columns (Princeton Separations Inc.) were used for excess dye extraction. Sequencing was performed initially in a total of 10 samples of L. schreiberi from different populations. We also sequenced two to three individuals of other seven Lacerta species from different localities to look for polymorphic positions.

\section{Detection of haplotypes by PCR-SSCP}

Using specific sequences of L. schreiberi, we designed PCR-SSCP primers to target a fragment of $170 \mathrm{bp}$ in the $3^{\prime}$ region. The selected forward and reverse primers were MosLs-F 5'-GTGCATCTGGATTTGAAACCTGCCAAC-3' and MosLs-R 5'-CTCTCACCTTTAAGGAGTTCAGGAGCAC-3', respectively. PCR conditions were 3 min at $95^{\circ} \mathrm{C}$ and 35 cycles of $1 \mathrm{~min}$ at $95^{\circ} \mathrm{C}, 30 \mathrm{~s}$ at $64^{\circ} \mathrm{C}$ and $30 \mathrm{~s}$ at $72{ }^{\circ} \mathrm{C}$, followed by a 2 -min extension at $72{ }^{\circ} \mathrm{C}$. The reaction mixture was made for $10 \mu \mathrm{L}$ total volume with $0.1 \mathrm{U}$ of Taq polymerase (Promega), $5 \mathrm{pmol}$ of each primer, $3 \mathrm{~mm}$ $\mathrm{MgCl}_{2}$ and $0.2 \mathrm{~mm}$ of each dNTP. For PCR checking prior to SSCP analysis, amplifications were electrophoresed in $2 \%$ agarose gels. Preliminary SSCP tests were performed with samples known to carry different sequences. Discrimination of conformers using the SSCP technique was accomplished as follows: $1 \mu \mathrm{L}$ of amplified DNA was mixed with $5 \mu \mathrm{L}$ of denaturing loading buffer (95\% deionized formamide, $10 \mathrm{~mm} \mathrm{NaOH}, 0.01 \%$ bromophenol blue and $0.01 \%$ xylene cyanol). Samples were denatured for $5 \mathrm{~min}$ at $95^{\circ} \mathrm{C}$ and kept on ice until gel loading. Five microlitre of sample was run in a $12 \%$ polyacrylamide gel (49:1 acrylamide : methylbisacrylamide) with $1 \times$ TBE buffer on a vertical electrophoresis system (BIORAD Protean II). The electrophoresis was performed at a constant voltage of $250 \mathrm{~V}$ and constant temperature $\left(12^{\circ} \mathrm{C}\right)$ for $15 \mathrm{~h}$. Routine SSCP separations always included previously typed samples that served as standards to ensure correct genotype scoring. The results were visualized by silver staining. Sequencing of four homozygous individuals for each allele collected in different populations was performed as described above in order to confirm identity of conformers.

\section{Data analysis}

Allele frequencies and measures of genetic variation were calculated using the GENETIX software, version 4.01 (Belkhir et al. 2000). Exact tests were used to analyse HardyWeinberg equilibrium with the help of the package GENEPOP (Raymond \& Rousset 1995). Estimates of nucleotide diversity $(\pi)$ were obtained with the DNASP 3.51 software (Rozas \& Rozas 1999) while C-mos nucleotide contents and the transition/tranversion ratio were calculated using the MEGA 2.1 software (Kumar et al. 2000). The different C-mos haplotypes observed in L. schreiberi and related outgroup species were used to construct a neighbour-joining tree also with the help of MEGA 2.1 software. To compare levels of C-mos and mitochondrial differentiation we followed the methodology described in Lovette \& Bermingham (2000). Nested clade phylogeographical analysis (NCPA) was applied to the C-mos data set as recently summarized by Templeton (2004).

\section{Results and discussion}

Partial C-mos gene sequences of 522 bp were obtained for eight lacertid species (six species included in the Lacerta sensu stricto group, L. schreiberi, L. bilineata, L. viridis, L. agilis, L. trilineata and L. pamphylica, and two outgroup taxa, L. lepida and L. monticola) representing 22 different sequences (Table 1 ). We found a total of 40 segregating sites from which 20 were parsimony informative and five out of the eight species exhibited nonsynonymous polymorphisms. Variable positions are distributed uniformly along the region studied and the transition/transversion substitution ratio was 2.3 , which is in agreement with values reported for other reptile and bird species (Saint et al. 1998; Lovette \& Bermingham 2000). Observed base composition averaged across the Lacerta species included in this study reflected a slight enrichment in adenines ( $\mathrm{T}=24.8 \%, \mathrm{C}=21.8 \%, \mathrm{~A}=30.6 \%, \mathrm{G}=22.8 \%$ ). No indels were found in any of these sequences when aligned among them. In addition, no indels were also found when sequences of L. schreiberi were compared with other species within the family Lacertidae. Nevertheless, $21 \mathrm{bp}$ [1271] plus $3 \mathrm{bp}$ [1461] corresponding to seven and one codons, respectively, were missing in all sequences when compared to the chicken sequence (numbers in brackets correspond to the first missing base in the Gallus C-mos nucleotide sequence). 
Table 1 Variable positions found in a 522-bp fragment of the C-mos gene in Lacerta schreiberi and an additional set of five related species ( $L$. bilineata, L. viridis, L. agilis, L. trilineata and L. pamphylica) and two outgroups (L. lepida and L. monticola). The fragment (170 bp) corresponding to the SSCP analysis is indicated on top of the table and relevant polymorphic positions in L. schreiberi are shaded. Boxes represent nucleotide variation that originates amino acid substitutions. Position 1 corresponds to position 472 of human C-mos gene (J00119)

\section{$\stackrel{\text { SSCP fragment }}{\longrightarrow}$}

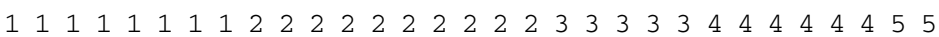

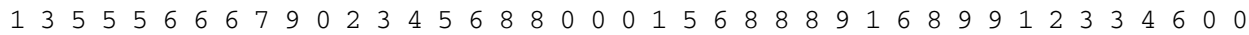

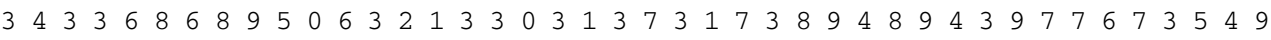

\begin{tabular}{|c|c|c|c|c|c|c|c|c|c|c|c|c|c|c|c|c|c|c|c|c|c|c|c|c|c|c|c|c|c|c|c|c|c|c|c|c|c|c|c|c|c|c|}
\hline L. schreiberi & Allele C & A & & & A & G & $\mathrm{T}$ & A & A & & $\mathrm{C}$ & A & & $\mathrm{C}$ & A & $\mathrm{C}$ & $\mathrm{T}$ & G & A & A & $\mathrm{T}$ & & $\mathrm{T}$ & $\mathrm{C}$ & G & G & $\mathrm{C}$ & $\mathrm{C}$ & $\mathrm{T}$ & $\mathrm{T}$ & A & A & C & $\mathrm{C}$ & $\mathrm{T}$ & $\mathrm{C}$ & $\mathrm{C}$ & $\mathrm{C}$ & & A & $\mathrm{T}$ & $\mathrm{TC}$ \\
\hline L. schreiberi & Allele C2 & . & . & & G & . & . & . & . & $\mathrm{C}$ & . & $\cdot$ & & . & $\cdot$ & . & . & . & . & & . & . & . & - & . & . & . & . & . & . & $\cdot$ & - & . & . & . & . & . & . & . & & . & . \\
\hline L. schreiberi & Allele C3 & . & . & - & - & . & . & . & . & $\mathrm{C}$ & . & • & 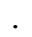 & . & $\cdot$ & . & $\cdot$ & • & . & & . & - & . & • & - & . & • & . & - & . & . & - & . & . & . & . & . & . & . & & . & . \\
\hline L. schreiberi & Allele A & . & . & . & . & . & . & . & . & . & . & . & . & . & . & . & . & . & . & . & . & . & . & . & . & . & - & . & . & . & . & . & A & . & . & . & . & . & . & • & . & . \\
\hline L. schreiberi & Allele B & . & . & . & . & . & . & . & . & . & . & . & $\cdot$ & . & ${ }^{\circ}$ & . & $\cdot$ & 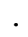 & . & - & . & - & - & e & 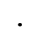 & . & - & . & 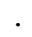 & 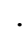 & . & 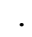 & . & . & . & . & . & . & . & $\mathrm{G}$ & C & \\
\hline L. schreiberi & Allele B2 & . & . & . & . & . & G & . & & . & . & . & . & . & • & . & . & • & . & . & . & . & . & . & ${ }^{\circ}$ & . & . & . & ${ }^{\circ}$ & . & . & . & . & . & . & . & . & . & . & G & C & . \\
\hline L. schreiberi & Allele D & . & . & . & . & . & . & . & . & . & . & . & . & . & . & . & . & . & . & . & . & . & . & . & . & . & . & . & . & . & . & . & . & . & $\mathrm{C}$ & . & . & . & . & . & . & . \\
\hline L. bilineata & Italy & . & . & & . & . & . & . & G & . & . & $\cdot$ & $\cdot$ & . & . & . & . & - & . & - & . & - & . & • & . & . & $\mathrm{T}$ & . & . & . & G & . & . & . & . & . & . & G & . & & $\mathrm{C}$ & . \\
\hline L. bilineata & Spain & . & . & & . & . & . & . & G & . & . & . & . & . & . & . & . & . & . & . & . & . & . & . & . & . & $\mathrm{T}$ & . & . & . & G & $\mathrm{C}$ & . & . & . & . & . & G & . & . & $\mathrm{C}$ & . \\
\hline L. bilineata & Sicily & . & . & & . & . & . & . & G & . & . & . & . & . & . & . & A & . & . & . & . & . & . & $\cdot$ & $\mathrm{T}$ & ]. & $\mathrm{T}$ & . & . & . & G & . & . & . & . & . & • & G & & . & $\mathrm{C}$ & . \\
\hline L. viridis & Croatia & . & . & & . & . & . & . & G & . & . & . & . & . & . & . & . & . & . & . & . & . & . & . & . & . & $\mathrm{T}$ & . & . & . & G & . & . & . & . & . & • & G & . & & C & . \\
\hline L. viridis & Hungary & . & . & & . & . & . & . & G & . & . & . & . & . & - & . & $\cdot$ & . & . & . & . & . & . & . & . & . & $\mathrm{T}$ & . & . & . & G & . & $\mathrm{T}$ & . & . & A & . & G & & & $\mathrm{C}$ & $\cdot$ \\
\hline L. viridis & Greece & . & . & & . & . & $\mathrm{C}$ & . & G & . & . & . & $\cdot$ & . & $\cdot$ & . & $\cdot$ & • & . & - & . & • & . & • & . & . & $\mathrm{T}$ & • & • & . & G & 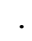 & . & $\mathrm{T}$ & . & . & • & G & & & C & $\cdot$ \\
\hline L. agilis & Austria & G & . & & . & . & . & . & G & - & . & $\cdot$ & $\mathrm{C}$ & . & & . & • & - & . & - & . & - & . & - & . & . & • & $\cdot$ & G & ]. & G & 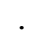 & . & . & . & . & $\cdot$ & . & . & & $\mathrm{C}$ & . \\
\hline L. agilis & Holland & G & . & . & . & . & . & . & G & . & . & $\cdot$ & $\mathrm{C}$ & . & . & . & . & . & . & . & . & - & . & · & . & . & . & - & . & . & G & . & . & . & . & . & . & - & . & . & $\mathrm{C}$ & A \\
\hline L. trilineata & Bosnia & G & . & . & . & . & . & . & G & . & . & . & . & . & . & . & . & . & . & . & . & . & . & . & . & . & . & . & . & . & G & . & . & . & . & . & . & G & . & 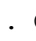 & $\mathrm{C}$ & . \\
\hline L. trilineata & Krete & G & . & - & . & . & . & . & G & . & . & - & . & . & . & . & . & . & . & . & . & . & - & $\cdot$ & . & . & . & . & . & . & G & & . & . & . & . & - & G & $\mathrm{T}$ & & $\mathrm{C}$ & I \\
\hline L. pamphylica & Turkey & G & . & . & . & $\mathrm{A}$ & . & $\cdot$ & G & . & . & . & . & . & . & . & . & . & . & . & . & . & . & . & . & . & . & . & . & . & G & & . & . & . & $\cdot$ & - & G & . & & C & \\
\hline L. pamphylica & Turkey & G & $\cdot$ & . & . & A & & $\mathrm{G}$ & G & . & . & - & . & . & . & . & . & . & . & & - & & . & & 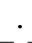 & . & & . & & & G & . & . & . & . & . & . & G & & & $\mathrm{C}$ & \\
\hline L. lepida ${ }^{-}-$ & Portūgāl & & A & & & . & - & $\cdot$ & $\bar{G}$ & & $\overline{-}$ & $\overline{\mathrm{G}}$ & & $\overline{\mathrm{G}}$ & & $\mathrm{T}$ & & & . & & - & & & & & $A$ & - & $\bar{A}$ & & $\overline{\mathrm{C}}$ & $\bar{G}$ & & & & - & - & - & $\bar{G}$ & . & 7 & $\overline{\mathrm{G}}$ & \\
\hline L. lepida & Portugal & $\cdot[$ & $\mathrm{A}$ & . & . & . & . & . & G & . & . & G & & G & & $\mathrm{T}$ & & & $\cdot$ & & . & $\cdot$ & $\cdot$ & & & A & . & A & - & C & G & & . & • & . & . & . & G & . & & G & - \\
\hline L. monticola & Portugal & G & . & . & & . & . & . & G & . & $\mathrm{T}$ & . & . & G & G & . & . & $\cdot$ & $\mathrm{C}$ & $\mathrm{C}$ & . & & $\mathrm{C}[$ & G & . & . & . & . & . & $\mathrm{C}$ & G & & . & . & . & $\cdot[$ & \begin{tabular}{|l|}
$G$ \\
\end{tabular} & G & . & 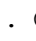 & G & \\
\hline
\end{tabular}

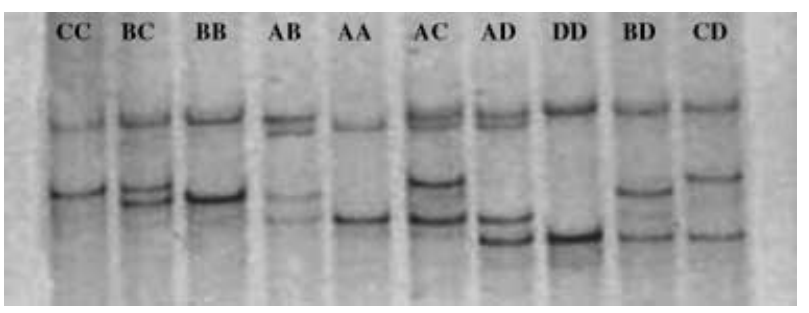

Fig. 2 Separation of allelic variants of the C-mos locus (170 bp) in Lacerta schreiberi by SSCP analysis on $12 \%$ polyacrylamide gels. Visualization was done by silver staining.

When the C-mos sequences obtained for the six species included in the Lacerta sensu stricto group were analysed with a sliding window of $100 \mathrm{bp}$ and $10 \mathrm{bp}$ steps (results not shown), two variable regions were found, one in the $5^{\prime}$ extreme and the other in the $3^{\prime}$ end of the amplified fragment. Due to a slightly higher number of polymorphic positions detected in the $3^{\prime}$ located variable region, we selected this portion of the C-mos gene for an extensive SSCP survey of 414 samples collected in 19 L. schreiberi populations encompassing the whole distribution area of this species. Our SSCP technique resolved a total of four alleles that were easily scored (A, B, C and D; Fig. 2), which were found in polymorphic frequencies $\left(p_{i}>0.01\right)$. The high resolving power of the SSCP technique was confirmed by sequencing four homozygous individuals for each SSCP allele which did not reveal additional variable positions. The phylogenetic relationships of the four SSCP alleles were easily determined by constructing a simple network and the ancestral haplotype was inferred from the sequences of related Lacerta species (Fig. 3). Two independent mutations in the ancestral haplotype are at the origin of alleles $\mathrm{B}(\mathrm{A} \rightarrow \mathrm{G}$ transition) and $\mathrm{C}(\mathrm{C} \rightarrow \mathrm{T}$ transition), while the two remnant alleles $\mathrm{A}$ and $\mathrm{D}$ derive from allele $C$ by a single point mutation each $(C \rightarrow A$ transversion and $\mathrm{T} \rightarrow \mathrm{C}$ transition, respectively). The mutations originating alleles A and B implicate an amino acid substitution, in both cases modifying the net charge of the C-mos gene product (Fig. 3).

The C-mos allelic frequencies, together with the expected heterozygosity and nucleotide diversity $(\pi)$, calculated for 
A

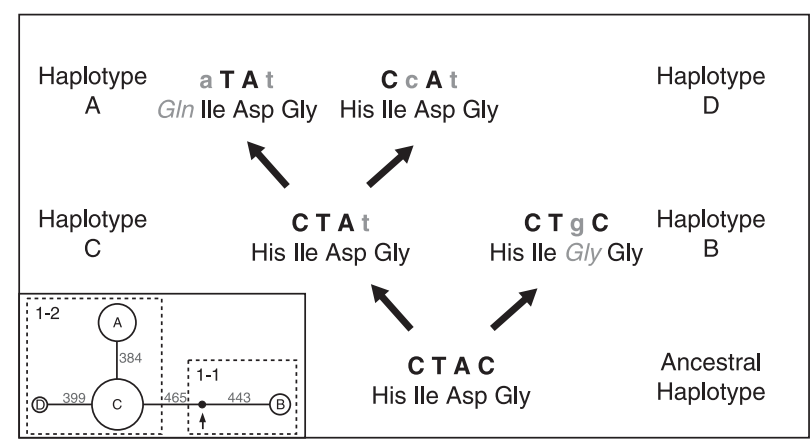

B

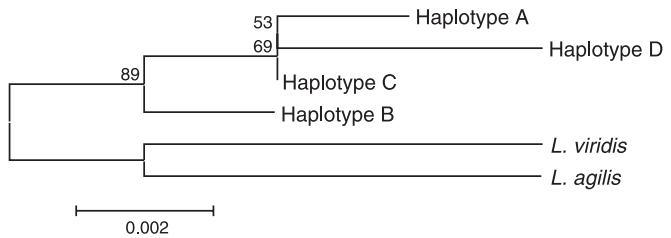

Fig. 3 (A) Phylogenetic relationships observed between the four SSCP C-mos haplotypes with the indication of nucleotide variable positions and corresponding amino acid substitutions. The ancestral allele was obtained by comparing C-mos sequences in Lacerta schreiberi with those from five closely related species. The inset shows the most parsimonious network where circle size is proportional to the frequency of each haplotype in the total sample. The root of the network is indicated by an arrow and corresponds to a missing haplotype (black circle). Numbers above lines correspond to the mutations that separate C-mos haplotypes. Nested clades designed for NCPA are represented with dashed lines. (B) Neighbour-joining tree relating Lacerta schreiberi C-mos haplotypes with two outgroup species. Bootstrap values (1000 replicates) are indicated.

the 19 L. schreiberi populations analysed in this study, are presented in Table 2. No deviations from Hardy-Weinberg expectations were detected over all populations. The most diverse populations were found along the Iberian central system, while a clear decrease in genetic diversity was detected in the northwestern region and in both the Portuguese southern isolates (Monchique and Cercal) and the Spanish central isolates (Guadalupe and Toledo). These results are in close agreement with a recent analysis of protein variation (Godinho et al. 2003) and also with the nucleotide diversity values reported for the mtDNA cytochrome $b$ (Paulo et al. 2001).

Estimates of population differentiation revealed strong structuring $\left(F_{\mathrm{ST}}=0.46\right)$ in the whole distribution area of $L$. schreiberi, but this value decreased dramatically when only five northwestern $\left(F_{\mathrm{ST}}=0.06\right)$ or three Spanish central system $\left(F_{\mathrm{ST}}=0.02\right)$ populations were analysed. A closer inspection of the allele frequency distribution in the Iberian Peninsula (Fig. 1 and Table 2) together with the analysis of phylogenetic relationships between alleles provide new insights into the evolution of the C-mos gene. Alleles B and
C differ by two mutations and the missing haplotype corresponds precisely to the root of the network (Fig. 3). On the other hand, allele B is basically confined to the Iberian central system, exhibiting higher frequencies in the Spanish locations. It is thus probable that allele B originated in this region during the prolonged geographical isolation of corresponding populations and that only recently was able to disperse to the Portuguese mountains where it occurs in low frequency. Allele $\mathrm{C}$ is the most frequent and widespread allele and originated the derived alleles $\mathrm{A}$ and $\mathrm{D}$ by simple point mutations. Allele A characterizes all northwestern populations and probably marks the recent postglacial expansion of L. schreiberi into this region (Paulo et al. 2002), while allele $D$ is restricted to the western Iberian mountains. This observation suggests that its origin may be related with the allopatric divergence of these populations, that was responsible for the emergence of a distinctive mtDNA coastal sublineage (Paulo et al. 2001) and a clear genetic imprint in several nuclear loci (Godinho et al. 2003 and unpublished results). NCPA of our C-mos data showed a clear lack of power due to the very simple haplotype tree analysed. Briefly, C-mos clade 1-1 (Fig. 3a) has no genetic variation and could not be included in the analysis, while clade 1-2 reflected long-distance colonization possibly coupled with subsequent fragmentation (results not shown).

Sequencing of a limited number of $L$. schreiberi samples for the 580-bp PCR-amplified fragment revealed three additional C-mos variants that can be considered subtypes of allele C (C2 and C3) and B (B2), all observed in the more diverse populations of central Iberian Peninsula (Table 1). Surprisingly, the sequencing of only two to three samples from related Lacerta species (including the more distant L. lepida, here used as an outgroup) showed a considerable number of variable positions in all of them, including multiple amino acid substitutions (Table 1). While a detailed investigation of the entire C-mos gene may eventually provide additional insights into the phylogenetic relationships and phylogeography of the lizard species included in the Lacerta sensu stricto group (Godinho et al. 2005), our present study combining limited DNA sequencing with the high resolving power of SSCP (Sunnucks et al. 2000) still captures the information provided by the Cmos gene and effectively demonstrates the utility of an additional nuclear marker to further improve our understanding of the evolutionary history of $L$. schreiber $i$ in the Iberian Peninsula.

Since its first report as a good candidate gene for deep phylogenetic studies (Graybeal 1994), nucleotide sequences from the C-mos proto-oncogene have been mostly used in the reconstruction of relationships between distantly related vertebrate taxa (Cooper \& Penny 1997; Saint et al. 1998; Harris et al. 1999; Hedges \& Poling 1999; Hughes \& Baker 1999; Barker et al. 2001; García-Moreno et al. 2003). 
Table 2 Number of individuals sampled $(N)$, allelic frequencies, number of alleles per population, expected heterozygosity $\left(H_{\mathrm{E}}\right)$ and nucleotide diversity $(\pi)$ at the $C$-mos locus. The mtDNA lineages were from Paulo et al. (2001) with the following correspondence: $\mathrm{A}_{1}$, coastal northern clade; $\mathrm{A}_{2}$, coastal southern clade; $\mathrm{B}_{1}$, inland northern clade; $\mathrm{B}_{2}$, inland southern clade

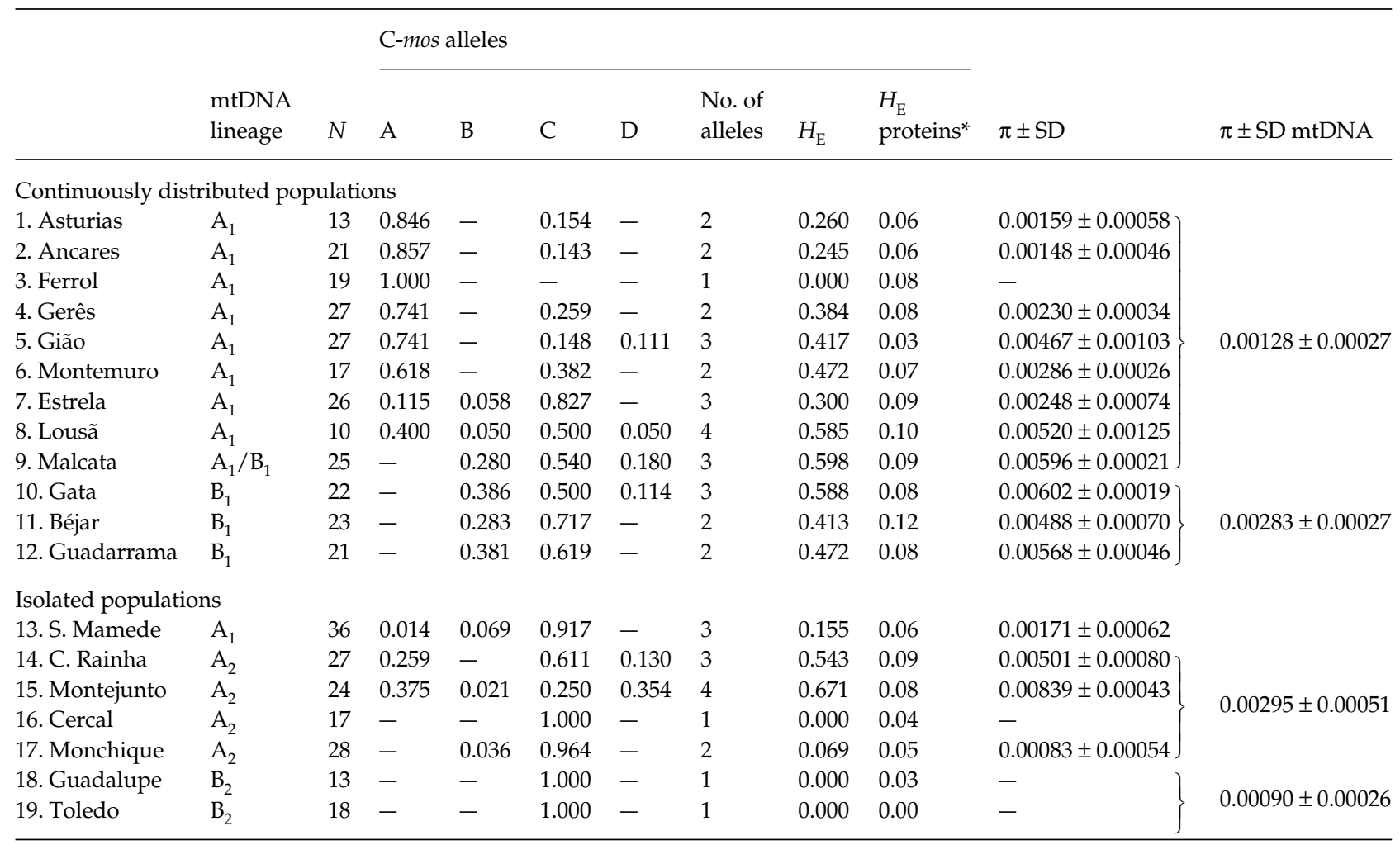

*Data from Godinho et al. (2003) and Godinho (2004); tdata from Paulo et al. (2001).

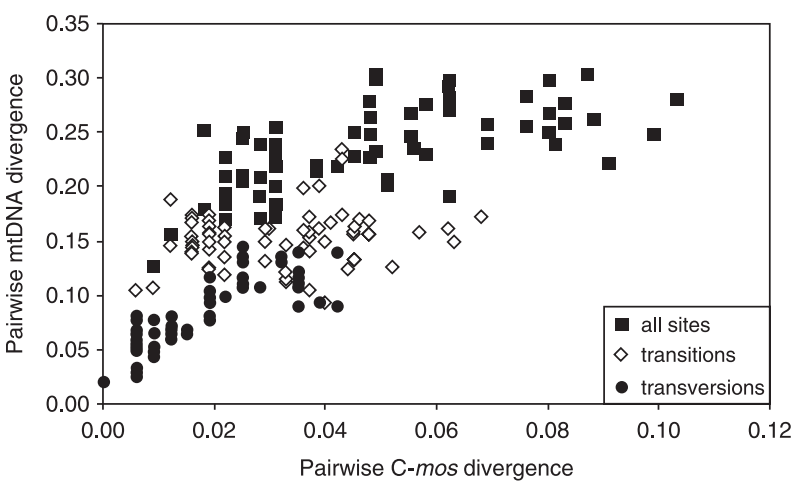

Fig. 4 Pairwise mitochondrial distances plotted against corresponding pairwise C-mos differentiation for 12 Lacertidae species.

Recently, however, Lovette \& Bermingham (2000) convincingly demonstrated its utility in resolving phylogenetic relationships at intermediate levels of divergence in birds. In order to evaluate the generalization of their observation, we followed the methodology described in Lovette \& Bermingham (2000) and plotted uncorrected mitochon- drial (cytochrome $b$ ) distances against the corresponding gamma-corrected C-mos divergence values for 12 species within the family Lacertidae (data available from the authors upon request) (Fig. 4). Our results are remarkable in the sense that they fully confirmed the observations described for birds, suggesting that C-mos nucleotide substitutions accumulate at a rate similar to that of mitochondrial transversion substitutions also in lizards, thus providing useful, independent and complementary markers in phylogenetic studies of Lacertidae. At a lower taxonomic level, our detailed study of a small (170 bp) fragment together with a more limited analysis of an extended 580bp fraction of the approximate $2 \mathrm{~kb}$ C-mos exon showed extensive intraspecific polymorphism, to our knowledge representing a rare example of variation in a highly conserved nuclear gene. Interestingly, two out of the four detected SSCP alleles implicated amino acid substitutions, resulting in two coding SNPs that can be used in future comparisons with noncoding SNPs and help in understanding the roles of population history and selection in shaping the genetic characteristics of this and other species. 


\section{Acknowledgements}

We thank Paulo Alexandrino, James Harris and Jorge Rocha for their manuscript comments. We are also indebted to two anonymous referees for providing useful suggestions that improved a previous version of this manuscript and to James Harris for reviewing the English. We thank the Portuguese Institute of Nature Conservation for the collecting permits in Portugal and the Junta de Castilla y León, Junta de Extremadura, Junta de Comunidades de Castilla-La Mancha, Xunta de Galicia and Principado de Asturias for the collecting permits in Spain. We are grateful to all colleagues that helped in the field work, especially Cristina Luís. RG worked under a PhD grant (PRAXIS XXI/BD/16087/98) from Fundação para a Ciência e a Tecnologia (FCT), Portugal, and is presently supported by a post-doctoral grant (SFRH/BPD/ 12723/2003). NF was supported by a sabbatical grant (SFRH/ BSAB/318/2002). This work was partially supported by FCT through POCTI/BIA/11174/98 and POCTI/BSE/40987/2001 grants.

\section{References}

Alexandrino J, Arntzen JW, Ferrand N (2002) Nested clade analysis and the genetic evidence for population expansion in the phylogeography of the golden-striped salamander, Chioglossa lusitanica (Amphibia: Urodela). Heredity, 88, 66-74.

Alexandrino J, Froufe E, Arntzen JW, Ferrand N (2000) Genetic subdivision, glacial refugia and postglacial recolonization in the golden-striped salamander, Chioglossa lusitanica (Amphibia: Urodela). Molecular Ecology, 9, 771-781.

Avise JC (1998) The history and purview of phylogeography: a personal reflection. Molecular Ecology, 7, 371-379.

Avise JC (2000) Phylogeography. The History and Formation of Species. Harvard University Press, Cambridge, Massachusetts.

Barker FK, Barrowclough GF, Groth JG (2001) A phylogenetic hypothesis for passerine birds: taxonomic and biogeographic implications of an analysis of nuclear DNA sequence data. Proceedings of the Royal Society of London. Series B, Biological Sciences, 269, 295-308.

Belkhir K, Borsa P, Chikhi L, Raufaste N, Bonhomme F (2000) GENETIX 4.01, logiciel sous Windows ${ }^{\mathrm{TM}}$ pour la génétique des populations. Laboratoire Génome et Populations, CNRS UPR 9060, Université de Montpellier II, Montpellier, France.

Blondel J, Aronson J (1999) Biology and Wildlife of the Mediterranean Region. Oxford University Press, New York.

Branco M, Ferrand N, Monnerot M (2000) Phylogeography of the European rabbit (Oryctolagus cuniculus) in the Iberian Peninsula inferred from RFLP analysis of the cytochrome $b$ gene. Heredity, 85, 307-317.

Branco M, Monnerot M, Ferrand N, Templeton AR (2002) Postglacial dispersal of the European rabbit (Oryctolagus cuniculus) on the Iberian Peninsula reconstructed from nested clade and mismatch analyses of mitochondrial DNA genetic variation. Evolution, 56, 792-803.

Comes HP, Abbott RJ (1998) The relative importance of historical events and gene flow on the population structure of a Mediterranean ragwort, Senecio gallicus (Asteraceae). Evolution, 52, 355367.

Cooper A, Penny D (1997) Mass survival of birds across the Cretaceous-Tertiary boundary: molecular evidence. Science, 275, 1109-1113.
García-Moreno J, Sorenson MD, Mindell DP (2003) Congruent avian phylogenies inferred from mitochondrial and nuclear DNA sequences. Journal of Molecular Evolution, 57, 27-37.

Gebauer F, Richter JD (1997) Synthesis and function of Mos: the control switch of vertebrate oocyte meiosis. BioEssays, 19, 23-28.

Godinho R (2004) Evolutionary history of the Schreiber's green lizard, Lacerta schreiberi: Phylogenetic analysis, reconstruction of processes of population expansion, contraction and miscigenation, and integration in the biogeographic context of northwestern Iberian Peninsula. PhD Thesis, University of Lisbon, Portugal.

Godinho R, Crespo EG, Ferrand N, Harris DJ (2005) Phylogeny and evolution of the green lizards Lacerta spp. (Squamata: Lacertidae) based on mitochondrial and nuclear DNA sequences. Amphibia-Reptilia, 26, 271-285.

Godinho R, Ferrand N, Crespo EG (2001) Phylogeography of the Iberian Schreiber's green lizard (Lacerta schreiberi): preliminary data on mitochondrial and nuclear markers reveal discrepant patterns. Mertensiella, 13, 33-39.

Godinho R, Paulo OS, Ferrand N et al. (2003) Major patterns of population differentiation in the Iberian Schreiber's green lizard (Lacerta schreiberi) inferred from protein polymorphism. Herpetological Journal, 13, 35-42.

Graybeal A (1994) Evaluating the phylogenetic utility of genes: a search for genes informative about deep divergences among vertebrates. Systematic Biology, 43, 174-193.

Harris DJ, Sinclair EO, Mercader NL, Marshall JC, Crandall KA (1999) Squamate relationships based on C-mos nuclear DNA sequences. Herpetological Journal, 9, 147-151.

Hedges SB, Poling LL (1999) A molecular phylogeny of reptiles. Science, 283, 998-1001.

Hudson RR, Turelli M (2003) Stochasticity overrules the 'threetimes rule': genetic drift, genetic draft, and coalescence times for nuclear loci versus mitochondrial DNA. Evolution, 57, 182-190.

Hughes JM, Baker AJ (1999) Phylogenetic relationships of the enigmatic hoatzin (Opisthocomus hoazin) resolved using mitochondrial and nuclear gene sequences. Molecular Biology and Evolution, 16, 1300-1307.

Kumar S, Tamura K, Jakobsen I, Nei M (2000) MEGA: Molecular Evolutionary Genetics Analysis. version 2.1. The Pennsylvania State University, University Park, Pennsylvania.

Lovette IJ, Bermingham E (2000) C-mos variation in songbirds: molecular evolution, phylogenetic implications, and comparisons with mitochondrial differentiation. Molecular Biology and Evolution, 17, 1569-1577.

Paulo OS, Dias C, Bruford MW, Jordan WC, Nichols RA (2001) The persistence of Pliocene populations through the Pleistocene climatic cycles: evidence from the phylogeography of an Iberian lizard. Proceedings of the Royal Society of London. Series B, Biological Sciences, 268, 1625-1630.

Paulo OS, Jordan WC, Bruford MW, Nichols RA (2002) Using nested clade analysis to assess the history of colonization and the persistence of populations of an Iberian lizard. Molecular Ecology, 11, 809-819.

Raymond M, Rousset F (1995) GENEPOP (version 1.2): population genetics software for exact tests and ecumenicism. Journal of Heredity, 86, 248-249.

Rozas J, Rozas R (1999) DNASP (version 3): an integrated program for molecular population genetics and molecular evolution analysis. Bioinformatics, 15, 174-175.

Sagata N (1997) What does Mos do in oocytes and somatic cells? BioEssays, 19, 13-20. 
738 R. GODINHO ET AL.

Sagata N, Oskarsson M, Copeland T, Brumbaugh J, Vande Woude GF (1988) Function of C-mos proto-oncogene product in meiotic maturation in Xenopus oocytes. Nature, 335, 519-525.

Saint KM, Austin CC, Donnellan SC, Hutchinson MN (1998) C-mos, a nuclear marker useful for squamate phylogenetic analysis. Molecular Phylogenetics and Evolution, 10, 259-263.

Sambrook E, Fritsch F, Maniatis T (1989) Molecular Cloning: A Laboratory Manual. Cold Spring Harbor Laboratory Press, Cold Spring Harbor, New York.

Sunnucks P, Wilson ACC, Beheregaray LB et al. (2000) SSCP is not so difficult: the application and utility of single-stranded conformation polymorphism in evolutionary biology and molecular ecology. Molecular Ecology, 9, 1699-1710.

Templeton A (2004) Statistical phylogeography: methods of evaluating and minimizing inference errors. Molecular Ecology, 13, 789-809.

Yew N, Strobel M, Woude GFV (1993) Mos and the cell cycle: the molecular basis of the transformed phenotype. Current Opinion in Genetics and Development, 3, 19-25.

Zhang D-X, Hewitt GM (2003) Nuclear DNA analyses in genetic studies of populations: practice, problems and prospects. Molecular Ecology, 12, 563-584.

This paper is part of the PhD thesis by Raquel Godinho on the evolutionary history of the endemic Iberian lizard Lacerta schreiberi. Vera Domingues worked on the project for her graduate thesis in Biology and has recently started up a project on the molecular biogeography of tropical and subtropical fishes of the Azores. Eduardo G. Crespo, professor at the Lisbon University, has been involved in several projects related with the study of amphibians and reptiles. Nuno Ferrand heads the CIBIO and is interested in a variety of questions in evolutionary and conservation genetics. 